\title{
Comparison of anionic membranes used to concentrate nitric acid to beyond the azeotropic mixture
}

\author{
C. Ponce-de-León*, R.W. Field \\ University of Bath, Department of Chemical Engineering, Bath, Claverton Down BA2 7AY, UK
}

Received 8 September 1999; received in revised form 1 December 1999; accepted 2 December 1999

\begin{abstract}
The electrolysis of concentrated nitric acid solutions was carried out in an electrochemical cell with parallel plates (FM01-LC ICI). An anionic membrane that permits the migration of nitrate ions under the influence of an electrical field separated the anodic and cathodic compartments. The current efficiency for the transported nitrate ions was evaluated for several membranes, at a constant current. All the membranes allowed the transport of nitrate ions at different current efficiencies, following the increase in acid concentration in the anodic compartment. This electroseparation membrane process concentrated nitric acid from $25 \%$ up to $90 \%$ in successive stages. A special case to be noted was when the acid concentration was near the azeotropic value. In this case, the acid concentration in the anodic compartment rose above the azeotropic value of $68.5 \%$, thus breaking the azeotrope mixture. It is expected that, for some niche applications, this process could be competitive with extractive distillation. (C) 2000 Elsevier Science B.V. All rights reserved.
\end{abstract}

Keywords: Electrodialysis; Nitric acid; Ion-exchange membranes; Separation

\section{Introduction}

Nitric acid is one of the main industrial reagents; its annual production reached $8 \times 10^{6}$ tonnes at the end of the 1970 's, ranking its production in the USA within the top 10 main reagents [1]. The size of the total world market production of nitric acid has currently reached 55-60 million tonnes. Ammonium nitrate, which is the major end-use for nitric acid, accounts for $80 \%$ or more of the world nitric acid markets [2], and it has been roughly estimated that fertilizer accounts for

\footnotetext{
* Corresponding author. Present address: Departamento de Química, Universidad Autonoma Metropolitana-Izt. Apdo Postal 55-534, 09340 Mexico, D.F., Mexico; Tel.: +52-5724-4670; fax: +52-5724-4666.

E-mail address: cpla@xanum.uam.mx (C. Ponce-de-León)
}

more than $85 \%$ of the world ammonium nitrate market. Thus, nitric acid consumption is greatly impacted by the state of the agricultural market. Other important end-use markets are the manufacturing of explosives and the manufacturing of intermediates for the production of fibres, plastics, elastomers and for organic synthesis.

The nitric acid industry is mature and has not grown appreciably in recent years. Indeed, in Western Europe, the industry has been declining because of concern about nitrate levels in groundwater, which have been affected by the level of fertilizer use [3]. The conventional production of the acid is by the catalytic oxidation of ammonia, giving a solution of $50-70 \%$ [4]. However, nitric acid at $100 \%$ is more efficient, particularly for the nitration of organic compounds. High acid concentrations can be achieved by extrac- 
tive distillation by means of a dehydrating agent such as sulfuric acid or magnesium nitrate in order to break the azeotropic mixture; however, the process involves further separations.

On the other hand, due to the economic and environmental benefit that the recovery of used acids represents, acid recovery processes have been increasing in recent years. The recovery of nitric, hydrochloric and sulfuric acids from chemical processes such as organic synthesis, the cleaning and dissolution of metals, among others, can be carried out by distillation, or alternatively, by a process using a membrane. In the latter process, the increase in concentration of nitric acid is performed by electrodialysis (ED), or by electro-electrodialysis (EED). ED is a process in which several anionic and cationic membranes alternate in an electrochemical cell in separate compartments. In the EED process, a cationic or anionic membrane is placed with each pair of electrodes within the cell. The EED process using an anionic membrane, which selectively transports nitrate ions to the anolyte [5-9], results in an increase in the concentration of nitric acid. In a recent study of simulated waste nitric acid solutions, the highest concentration of nitric acid reached by EED using an anionic perfluorinated membrane was $10 \mathrm{M}$ [10].

Ideally, during ED, it is desirable that the electrolysis of water, i.e. the evolution of hydrogen and oxygen, takes place in the cathode and the anode, respectively, but in the EED of nitric acid, nitrate ions can be reduced to nitrite and further to ammonia. Simultaneously, protons can be reduced to hydrogen gas. Several authors have studied the reduction of nitrate ions in alkaline [11-16] and acidic media [17-19]. However, these studies used low nitrate concentrations $(<1 \mathrm{M})$. Harrar et al. carried out one of the few studies using high nitrate concentrations; they used a divided cell to produce $\mathrm{N}_{2} \mathrm{O}_{5}$, with anolyte solutions of $\mathrm{N}_{2} \mathrm{O}_{4}$ in approximately $99 \%$ nitric acid, and with catholyte solutions of the acid alone. The cathodic reaction was the production of $\mathrm{N}_{2} \mathrm{O}_{4}$, which in theory, after separation from water, could be recirculated and used as the anolyte feedstock [20,21].

The principal aim of this paper was to study the breaking of the nitric acid azeotrope using an electromembrane process, and to analyze parameters such as membrane duration, cathodes, and the influence of the cathodic reaction during the EED process. Our ex- perimental evidence suggests that the main cathodic reaction is the formation of $\mathrm{NO}_{2}$ in equilibrium with $\mathrm{N}_{2} \mathrm{O}_{4}$ and the further reduction of $\mathrm{NO}_{2}$ to the $\mathrm{NO}_{2}{ }^{-}$ ion.

\subsection{Membrane current efficiency}

For a membrane process, the current efficiency is the amount of charge transported through the membrane by a specific contra ion $\left(\mathrm{NO}_{3}{ }^{-}\right)$, per total charge, passed through the membrane. The integral current efficiency (ICE) is an average value of the current efficiency over a period of time. The mathematical definition is

$\eta_{\mathrm{ICE}}=\frac{N z \mathfrak{I}}{\int_{0}^{t} i \mathrm{~d} t}$

However, in practice, it is calculated as

$\eta_{\mathrm{ICE}}=\frac{N(t)-N(0)}{F(t)}$

This is valid for systems that are geometric and hydrodynamically similar due to their historical dependence ( $N$ increases with time). Where $N, z, F$ and $\mathfrak{I}$ are the number of moles, the charge, the number of Faradays and the Faraday's constant, respectively; $N(t)$ and $N(0)$ are the number of moles at the times $t$ and 0 , respectively.

The differential current efficiency (DCE), on the other hand, is calculated on a differential element of time. It represents the value of the current efficiency over a very small period of time rather than that of an average over a considerable period of time.

The mathematical definition is

$\eta_{\mathrm{DCE}}=\frac{\mathrm{d} N}{\mathrm{~d} t} \frac{z \mathfrak{I}}{i}$

In an experimental situation, however

$\eta_{\mathrm{DCE}}=\frac{N(t+1)-N(t)}{F(t+1)-F(t)}$

It is important to note that $\eta_{\mathrm{DCE}}$ is highly sensitive to small experimental errors and fluctuations.

For an anion exchange membrane (AEM), the charge transported by protons from one molecule of water to another within the membrane limits the current efficiency. Thus, acids tend to diffuse at higher 
rates than other ions, particularly when the water content of the membrane is high.

\section{Experimental}

The electrochemical cell used was a filter press type with parallel plates (ICI FMO-1 LC), operated in batch with Calomel electrodes as a reference. Fig. 1 shows an outline of this cell with two compartments divided by an anionic membrane. The flow system was arranged as shown in Fig. 2. Flow within the cell was kept at approximately $66 \mathrm{~cm} \mathrm{~s}^{-1}$. Each electrode had a turbulence promoter made of poly(tetrafluoroethylene) (PTFE). The cathode electrodes used were a stainless steel 304-L, a stainless steel 316 and a 'Hastelloy' alloy. Niobium platinized in the form of a grill 'Lantern Blade' was used as an anode. The complete description of this cell, its characteristics and local variations of transport have been outlined in detail in the literature [22-24]. A standard dc power supply was used to apply constant current. The anionic membranes used were all commercially available: AW and ARA from
Solvay, France, Raipore 5035 and Raipore 6030 from Pall, UK, and ACS and AFN7 from Tokuyama, Japan. The AW, ARA, ACS and AFN7 membranes have been used in several ED studies and their characteristics such as ionic exchange capacity, water content, transport number and nature of ionic sites can be found in the literature [25-29]. The Raipore membranes 5035 and 6030 are for the separation of acids with low proton leakage. The membrane 6030 was specially manufactured for the experimental production of $\mathrm{N}_{2} \mathrm{O}_{5}$ with a thickness of 6-7 mil; in comparison, the rest of the membranes have a thickness within the range of 2-4 mil. The ionic exchange sites of such Raipore membranes were quarternized benzylamine graft on a fluorinated polymer film [30]. In the experiment with a three-compartment cell, a cationic Raipore 4010 membrane protected the cathode. On the other hand, tubing, valves, and heads of the centrifuge bombs were manufactured from PTFE. The $\mathrm{NO}_{2} / \mathrm{N}_{2} \mathrm{O}_{4}$ gas mixture, which formed in the catholyte compartment during the EED experiments, was diluted with nitrogen. This mixture was passed through a gas scrubber containing sodium hydroxide, in order to neutralize the

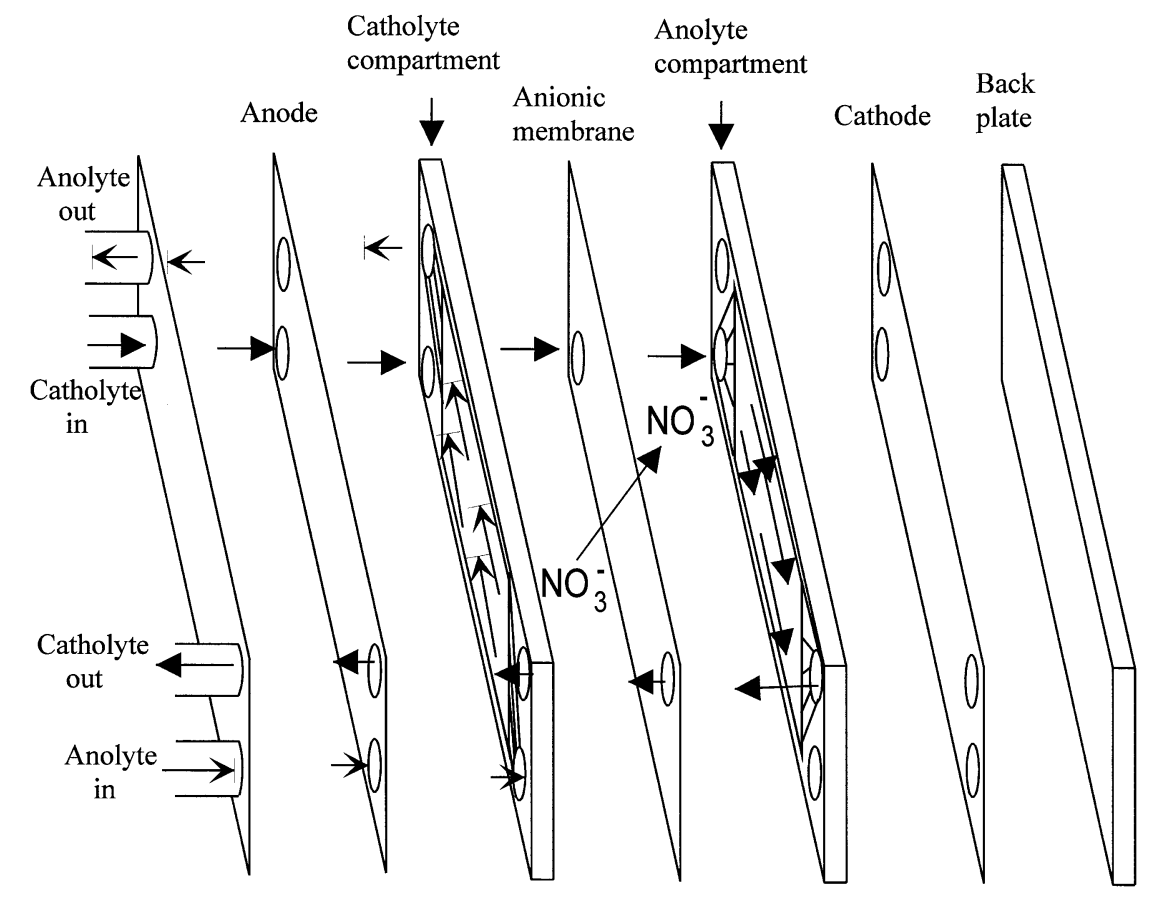

Fig. 1. Schematic diagram of a two-compartment cell for EED experiments. 


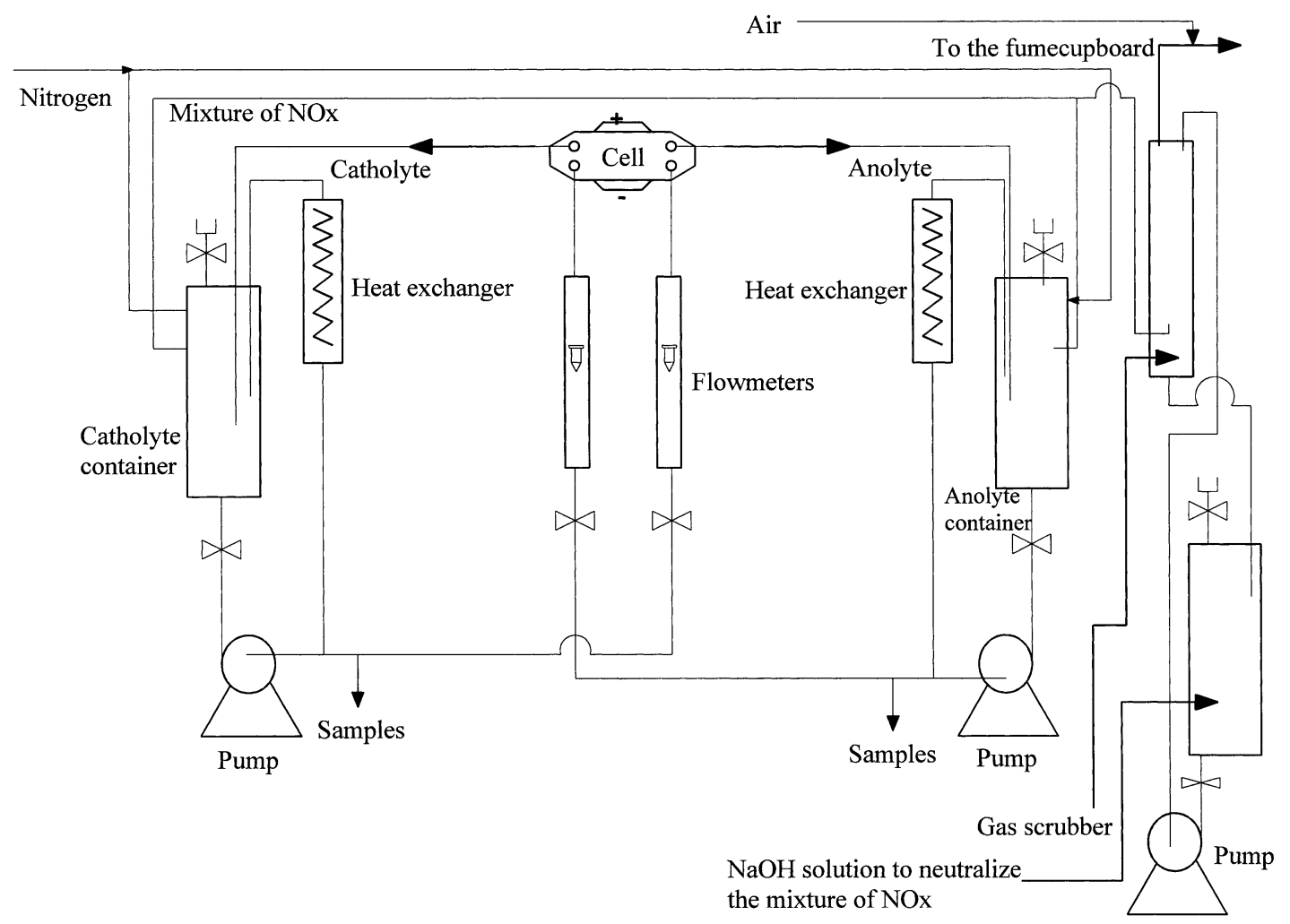

Fig. 2. Outline of the experimental rig.

$\mathrm{NO}_{x}$ gases. The remaining gases, including the oxygen produced in the anolyte, were diluted to a ratio of 1:5 with air and sent through the fume cupboard.

During electrolysis, samples from the catholyte and the anolyte were taken at regular intervals. The determination of the total acid was carried out by standard volumetric analysis [31]. An in-line density meter measured the density of the acid. The concentration of the $\mathrm{NO}_{2}{ }^{-}$ion was determined by the addition of $0.1 \mathrm{~N}$ ammonium, and an excess of ceric sulfate solution, followed by the reverse titration with $0.1 \mathrm{~N}$ sodium thiosulphate [31]. The nitric acid was of a technical grade and the other reagents were of an analytic grade.

\section{Results and discussion}

\subsection{Electrodes}

Three cathode electrodes were tested, a stainless steel 316, a stainless steel 304-L and a Hastelloy alloy.
The current efficiencies ICE and DCE were slightly larger with stainless steel electrodes than with the Hastelloy electrode. However, the stainless steel 316 electrode lost $0.55 \%$ of its weight after $700 \mathrm{~min}$ at $300 \mathrm{~mA} \mathrm{~cm}^{-2}$. With a stainless steel 304-L, there was no change in weight under the same conditions. Similarly, the anode electrode made of platinized niobium kept a constant weight.

\subsection{Electrochemical reactions}

Concentrated nitric acid has not been studied extensively with regard to electromembrane processes. Most literature relates to nitrate recovery, generally describing low concentration feed streams as applicable to the water industry. The recommended level of nitrates in drinking water is $<25 \mathrm{mg} \mathrm{l}^{-1}(\sim 0.004 \mathrm{M})$. Since electromembrane processes are suitable for depleting ions from concentrated solutions, leaving behind a very dilute solution of ions, this has prompted 
nitrate recovery via electromembrane processes in recent years [8,32,33]. Nitrates can form nitrites, nitriles and nitrosamines, and various mechanisms have been proposed for the nitrate reduction pathway, which increases in complexity with the presence of metal ions in the system. Despite the fact that this mechanism has not been fully understood yet, overall two key reduction products, which are nitrite and ammonium, have been highlighted at low concentrations $(<1.2 \mathrm{M})$. At higher concentrations $(>2 \mathrm{M})$, the cathodic reactions depend mainly upon the predominant species in the solution. At concentrations below $10 \mathrm{M}$ $(\sim 50 \%)$, the evolution of hydrogen gas is the main reaction, since the acid is completely dissociated. As the concentration increases, the degree of ionization is lower. The predominant form of nitric acid at $68.5 \%$ (azeotropic mixture) is the hydrated and dehydrated $\mathrm{NO}_{2} \mathrm{OH}$ species. Under these conditions, the evolution of hydrogen gas does not take place at an appreciable rate, but the main reaction is the reduction of the dehydrated nitric acid and the nitrate ions. On the other hand, it is assumed that the only anodic reaction is the oxidation of water [19].
The aforementioned literature research shows that the reduction of nitrate leads to $\mathrm{NO}_{2}$ nitrite molecule and its reduction forms $\mathrm{NO}_{2}{ }^{-}$nitrite ions. Further reduction of these ions results in ammonia. At high concentrations, we found that the first reduction product, that is, $\mathrm{NO}_{2}$, was in equilibrium with $\mathrm{N}_{2} \mathrm{O}_{4}$. However, this mixture was not analyzed during the electrolysis of the azeotropic mixture. Instead, the concentration of $\mathrm{NO}_{2}^{-}$nitrite ions, both in the catholyte and in the anolyte, was determined. Fig. 3 shows the change in concentration of the $\mathrm{NO}_{2}{ }^{-}$ion versus catholyte concentration during the EED of nitric acid. It can be seen that the concentration of nitrite ions increased during electrolysis. The current efficiency, assuming the cathodic reaction $\mathrm{NO}_{3}{ }^{-}+2 \mathrm{H}^{+}+2 \mathrm{e}^{-} \rightarrow \mathrm{NO}_{2}{ }^{-}+\mathrm{H}_{2} \mathrm{O}$ instead of the one-electron reaction $\mathrm{NO}_{3}{ }^{-}+2 \mathrm{H}^{+}+\mathrm{e}^{-} \rightarrow 1 / 2 \mathrm{~N}_{2} \mathrm{O}_{4}$ (g) $+\mathrm{H}_{2} \mathrm{O}$, was 0.80 during the first $2 \mathrm{~h}$ and then it dropped. Since the $\mathrm{NO}_{2}$ molecule was the reactant for the $\mathrm{NO}_{2}{ }^{-}$, the equilibrium conditions of the reaction $2 \mathrm{NO}_{2}=\mathrm{N}_{2} \mathrm{O}_{4}$ affected the concentration of the nitrite ions in the solution. The depletion of nitrite ions after $2 \mathrm{~h}$ was attributed to a shift to the right in the above

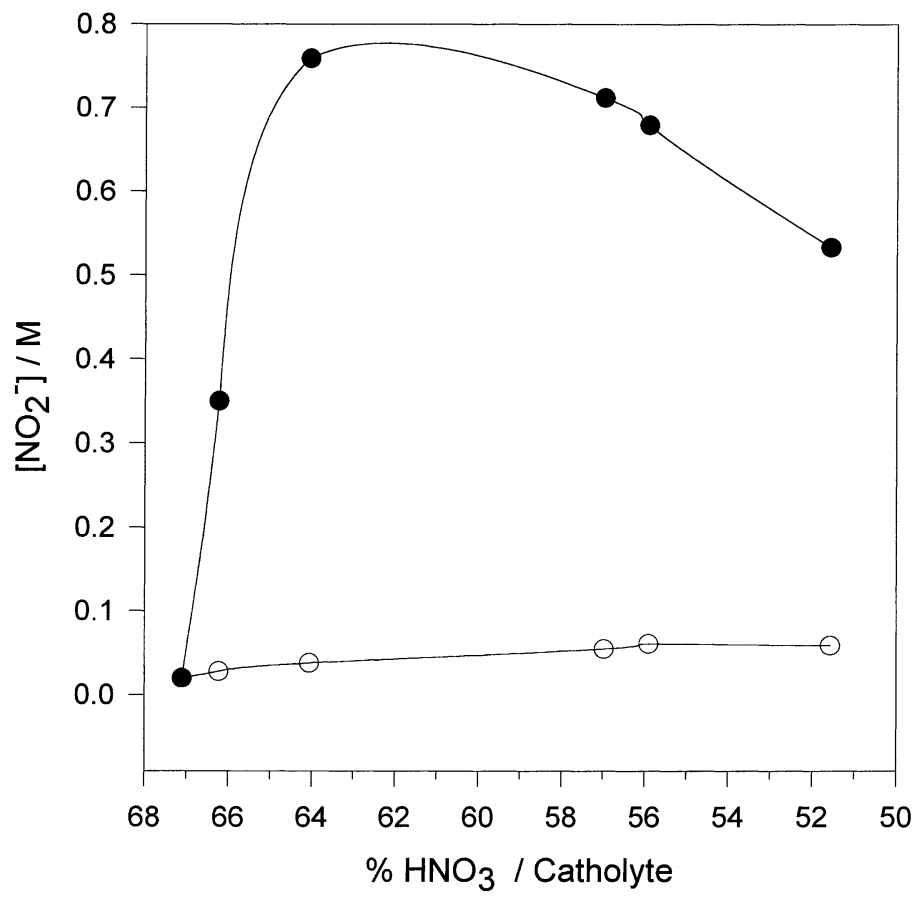

Fig. 3. Evolution of $\mathrm{NO}_{2}{ }^{-}$ion for both catholyte $\mathrm{O}$ and anolyte $\bigcirc$ with the change in nitric acid concentration in the catholyte compartment. The electrolysis was carried out using an AW membrane at a current density of $300 \mathrm{~mA} \mathrm{~cm}^{-2}$ in a two-compartment cell. 


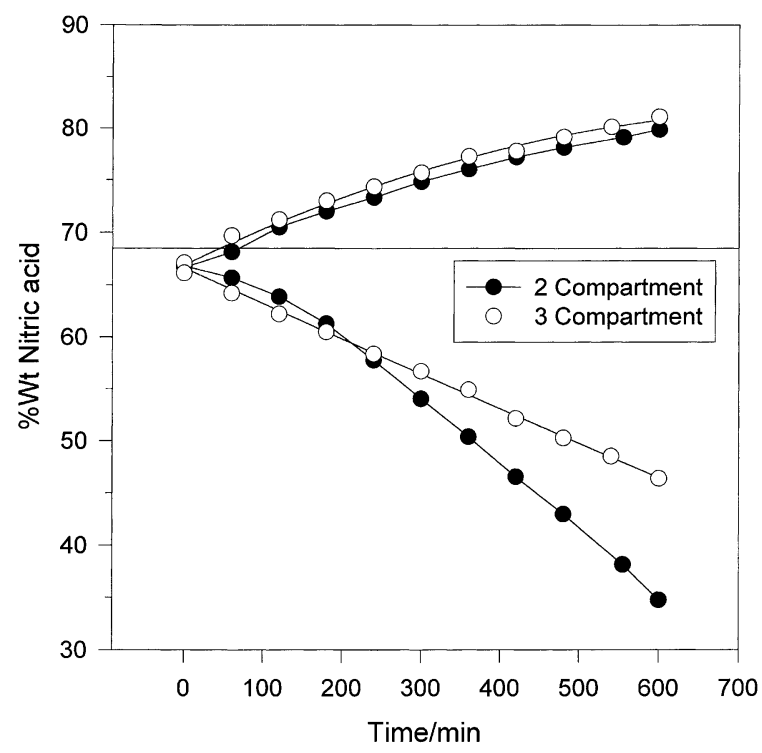

Fig. 4. Change in the acid concentration with time in both anolyte and catholyte during an electrolysis in a two- and a three-compartment cell. In the two-compartment cell, the membrane used was an AW, whereas in the three-compartment cell, the membranes were: anionic AW, cationic Raipore 4010. In both experiments, the current density was at $300 \mathrm{~mA} \mathrm{~cm}^{-2}$.

reaction due to the increase in temperature from 20 to $30^{\circ} \mathrm{C}$ during $\mathrm{EED}$, leading from the cathodic reduction of nitrate to the formation of $\mathrm{N}_{2} \mathrm{O}_{4}$ as a main product. Fig. 4 gives an example of the change in the concentration of nitric acid in the catholyte and in the anolyte.

It was observed that hydrogen evolution started only when the catholyte concentration dropped below $45-50 \%$, thus suggesting that nitrate reduction to $\mathrm{NO}_{2}=\mathrm{N}_{2} \mathrm{O}_{4}$ was the main cathodic reaction at a concentration above $50 \%$ nitric acid. Harrar et al. did not observe hydrogen evolution at $99 \%$ nitric acid; however, they did produce $\mathrm{N}_{2} \mathrm{O}_{4}$ at the cathode [20,21].

The changes in color in the catholyte during the EED of the acid were interesting. During the first hour at concentrations between 55 and $67 \%$, the color of the solution changed from transparent to dark brown in equilibrium with red gases. This was due to the presence of the $\mathrm{N}_{2} \mathrm{O}_{4}$ species, which is red at $21^{\circ} \mathrm{C}$ when it is in equilibrium with $\mathrm{NO}_{2}$ gas. In the second and third hours, the change in color was from dark brown to dark green (45-55 w/w\%). This was probably due to the presence of species such as $\mathrm{NO}_{2} \mathrm{OH}$, since in amounts of less than $2 \%$, it produces a greenish blue solution. As the concentration fell, the catholyte turned light blue (35-45\%). Finally, at a concentration of $25 \%$, the solution was slightly pink. These changes in coloration were due to a complex mixture of nitrogen oxides.

This change in catholyte color could be avoided by protecting the cathode with a cationic membrane. In an experiment carried out in a three-compartment cell, hydrogen ions migrated from the middle nitric acid compartment towards the cathode through the cationic membrane where the solution in contact with the cathode was only sulfuric acid. Therefore, it was assured that the cathodic reaction was simply the evolution of hydrogen. A cationic Raipore 4010 membrane in contact with a sulfuric acid $1 \mathrm{M}$ solution protected the cathode. In the middle compartment, the azeotropic mixture was in contact with the cationic membrane (catholyte side) and with an AW anionic membrane (anolyte side). In this case, no changes in color in the catholyte were observed. The changes in acid concentration were similar to the changes observed in a three-compartment cell as shown in Fig. 4. It should be emphasized, however, that the concentration of nitric acid in the catholyte dropped faster in a two-compartment cell due to cathodic reduction.

\subsection{Selection of membrane for the EED of nitric acid}

Several anionic membranes used in the EED of nitric acid are compared in Table 1 . In all experiments, the starting concentration of both the catholyte and the anolyte was between 65 and $70 \%$. All the membranes transported nitrate ions so that the concentration of the anolyte surpassed the azeotropic value $(68.5 \%)$ as can be seen from the column of maximum concentration in Table 1. The DCE varied with the concentration difference and the first column in Table 1 shows the DCE for each experiment when the difference in concentration between the anolyte and the catholyte was approximately $20 \%$. Table 1 also shows the fluxes in $\mathrm{NO}_{3}{ }^{-}, \mathrm{H}^{+}$, and $\mathrm{H}_{2} \mathrm{O}$, calculated from a mass balance during the experiment. From these values, it is possible to evaluate the number of water molecules per nitrate ion that migrated through the membrane. It should be noted that hydrogen and nitrate ions traveled across the membrane as solvated ions; therefore, 
Table 1

Comparison of different anionic membranes ${ }^{\mathrm{a}}$

\begin{tabular}{|c|c|c|c|c|c|c|c|}
\hline Membrane & DCE & $\begin{array}{l}\text { Flux } \mathrm{NO}_{3}^{-} \\
\left(\mathrm{mol} \mathrm{m}^{-2} \mathrm{~s}^{-1}\right)\end{array}$ & $\begin{array}{l}\text { Flux } \mathrm{H}^{+} \\
\left(\mathrm{mol} \mathrm{m}^{-2} \mathrm{~s}^{-1}\right)\end{array}$ & $\begin{array}{l}\text { Flux } \mathrm{H}_{2} \mathrm{O} \\
\left(\mathrm{mol} \mathrm{m}^{-2} \mathrm{~s}^{-1}\right)\end{array}$ & $\mathrm{H}_{2} \mathrm{O} / \mathrm{NO}_{3}$ & $\begin{array}{l}\text { Maximum } \\
{\left[\mathrm{HNO}_{3}\right] \mathrm{M}(\%)}\end{array}$ & $\begin{array}{l}E_{\mathrm{S}} \\
\left(\mathrm{kW} \mathrm{h} \mathrm{kg}^{-1}\right)\end{array}$ \\
\hline AFN7 & 0.27 & 0.0087 & -0.023 & 0.021 & 2.4 & $16.0 \mathrm{M}: 71 \%$ & 3.54 \\
\hline ARA & 0.41 & 0.0129 & -0.019 & 0.023 & 1.7 & $16.5 \mathrm{M}: 73.4 \%$ & 4.66 \\
\hline Raipore 5035 & 0.48 & 0.0152 & -0.016 & 0.023 & 1.5 & $17.0 \mathrm{M}: 75.4 \%$ & 3.10 \\
\hline ACS & 0.52 & 0.0165 & -0.015 & 0.025 & 1.5 & $16.4 \mathrm{M}: 73 \%$ & 2.86 \\
\hline $\mathrm{AW}$ & 0.60 & 0.0192 & -0.0124 & 0.025 & 1.3 & $17.9 \mathrm{M}: 78.9 \%$ & 1.77 \\
\hline Raipore 6030 & 0.83 & 0.0262 & -0.0163 & 0.026 & 1.0 & $18.0 \mathrm{M}: 79.3 \%$ & 1.41 \\
\hline
\end{tabular}

\footnotetext{
${ }^{a}$ The initial concentration of the catholyte and the anolyte for all the cases was between 65 and $70 \%$. The DCE was calculated when
} the concentration difference was $20 \%$. The current density was $300 \mathrm{~mA} \mathrm{~cm}^{-1}$.

the ratios $\mathrm{H}_{2} \mathrm{O} / \mathrm{NO}_{3}{ }^{-}$and $\mathrm{H}_{2} \mathrm{O} / \mathrm{H}^{+}$provide an estimation of the number of water molecules accompanying each ion as they migrated. The minus sign in the protons' column indicates that $\mathrm{H}^{+}$ions migrated from the anolyte to the catholyte. The cell potential and the current efficiency were used to calculate the specific energy, $E_{\mathrm{s}}$, during the process. As can be seen from Table 1, the energy consumption varied within the range $1.41-4.66 \mathrm{~kW} \mathrm{~h} \mathrm{~kg}^{-1}$. The $E_{\mathrm{s}}$ values for electrochemical processes such as the removal of $\mathrm{Cr}(\mathrm{IV})$ and the Monsanto process (hydrodimerization of acrylonitrile) are 11.0 and $6.7 \mathrm{~kW} \mathrm{~h} \mathrm{~kg}^{-1}$, respectively, whereas the desalination of water is $1.4 \times 10^{-3} \mathrm{~kW} \mathrm{~h} \mathrm{~kg}^{-1}$ [34]. Although the $E_{\mathrm{S}}$ values in Table 1 are within the same order of magnitude as in an electrochemical process, they are high in comparison with the desalination of water, which is an ED process.

In general, it was observed that the values of DCE diminished upon increasing the concentration in the anolyte for all the experiments. Fig. 5 shows the change in concentration for the anolyte and the catholyte for the EED carried out with the Raipore 6030 membrane; the inset in the figure shows the changes in both ICE and DCE. The efficiencies decreased as the concentration difference increased, the DCE decreased rapidly which was an indication of the instant performance of the membrane, whereas the ICE was the accumulative value of the efficiency from the beginning of the experiment.

Clearly, the Raipore 6030 membrane from Pall showed a higher DCE and a higher nitrate ion flux than the rest of the membranes under the conditions used. It exhibited three times more nitrate flux than the AFN7 membrane, which had the lowest flux. In addition, a mass balance for the ratio $\mathrm{H}_{2} \mathrm{O} / \mathrm{NO}_{3}$ demonstrated that the acid concentration within the membrane was the highest. On the contrary, the anionic membrane AFN7 had the lowest acid concentration inside the membrane and the lowest DCE. In addition, proton leakage in the AFN7 membrane was 1.4 times higher than in the Raipore 6030 membrane. Thus, it made the AFN7 membrane more suitable for a dialysis process, since high proton leakage is necessary for dialysis. The flux of water towards the anolyte across the membranes remained practically constant, differing only by a factor of 1.2 among these two extreme membranes.

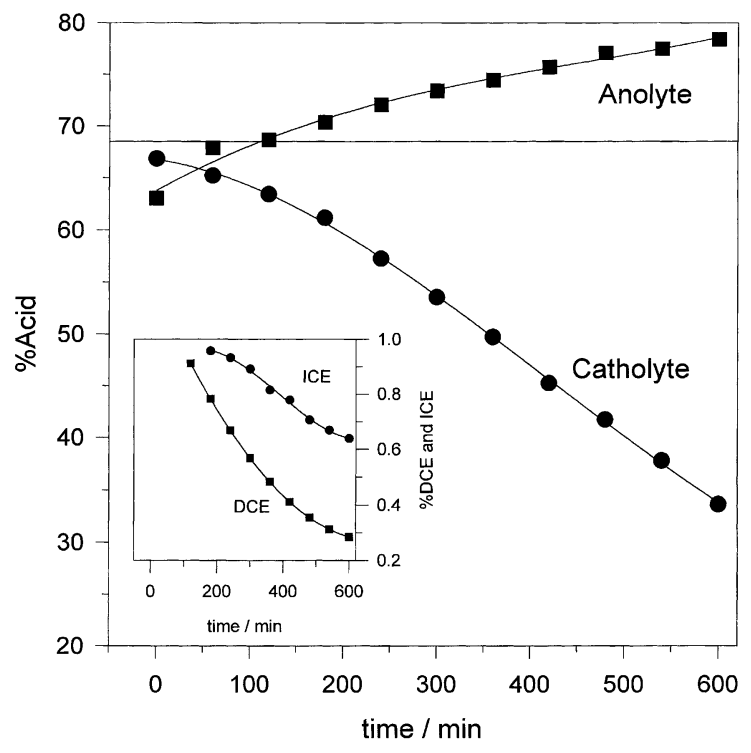

Fig. 5. Change in the acid concentration with time in both anolyte and catholyte. The inset shows the current efficiencies ICE and DCE for an electrolysis at a current density of $300 \mathrm{~mA} \mathrm{~cm}^{-2}$ using a Raipore 6030 membrane from Pall. 
Table 2

Experiments with a Raipore 6030 membrane $\left(300 \mathrm{~mA} \mathrm{~cm}^{-2}\right)$

\begin{tabular}{|c|c|c|c|c|c|c|c|}
\hline Experiment & $\begin{array}{l}\text { Catholyte } \\
\text { initial }(\%)\end{array}$ & $\begin{array}{l}\text { Catholyte } \\
\text { final }(\%)\end{array}$ & $\begin{array}{l}\text { Anolyte } \\
\text { initial }(\%)\end{array}$ & $\begin{array}{l}\text { Anolyte } \\
\text { final }(\%)\end{array}$ & $\begin{array}{l}\text { DCE } \\
(\Delta 9 \mathrm{M})\end{array}$ & $\begin{array}{l}\text { Duration } \\
\text { (h) }\end{array}$ & $\begin{array}{l}\text { Accumulative } \\
\text { time }(\mathrm{h})\end{array}$ \\
\hline \multicolumn{8}{|c|}{ (a) Constant catalytic concentrations } \\
\hline 1 & 25 & 25 & 61 & 66 & 0.00 & 6 & 6 \\
\hline 2 & 35 & 35 & 64 & 72 & 0.20 & 7.2 & 13.2 \\
\hline 3 & 45 & 45 & 61 & 71 & 0.50 & 6.5 & 19.7 \\
\hline 4 & 55 & 55 & 62 & 74 & 0.65 & 6.4 & 26.1 \\
\hline \multicolumn{8}{|c|}{ (b) Comparison of new and used membranes } \\
\hline Used & 65 & 50 & 74 & 86 & 0.55 & 13 & 39.1 \\
\hline New & 64 & 50 & 68 & 77 & 0.80 & & \\
\hline
\end{tabular}

\subsection{Experiment at constant catholyte concentration}

Since the Raipore 6030 membrane showed the highest nitrate ion flux, it was then chosen to carry out a series of long-term experiments with different constant catholyte concentrations, in order to determine the degree of membrane degradation. In each experiment, the catholyte concentration was kept at the following constant values: $25,35,45$ and $55 \%$, whereas the initial concentration of the anolyte was approximately $60 \%$ for each experiment. The experiments were carried out using the same piece of membrane, starting with the lowest acid concentration. The results are shown in Table 2a. As can be seen from the table, the DCE values depended on the initial catholyte concentration; the DCE increased as the concentration difference between the catholyte and the anolyte diminished. This series of experiments showed that the concentration of the anolyte overcame the azeotropic value $(68.5 \%)$ only when the catholyte concentration was higher than 35\% (Experiment 2). However, in this case, the DCE value was only 0.20 , with a final concentration difference of approximately $35 \%$. The highest DCE value was 0.65 with a final concentration difference of $20 \%$ at the end of the fourth experiment, i.e., after $26 \mathrm{~h}$ of operation at $300 \mathrm{~mA} \mathrm{~cm}^{-2}$. The experiments suggested that, if the concentration of catholyte and anolyte differed by more than $25 \%$, a staged process would be necessary.

A comparison of new and used membranes is given in Table $2 \mathrm{~b}$ using data obtained with both new and used Raipore 6030 membranes. The used membranes had been submitted to a density current of $300 \mathrm{~mA} \mathrm{~cm}^{-2}$ in the experiment in the previous section, for $26 \mathrm{~h}$.
The initial catholyte conditions were the same for both experiments; however, the initial anolyte concentration was different, that is, $74 \%$, for the used membrane and $68 \%$ for the new membrane. As a result, at the end of the experiments, the anolyte with the used membrane reached $86 \%$ concentration and the anolyte with the new membrane reached $74 \%$. However, the DCE values in both cases were different; the new membrane had a current efficiency of 0.80 , whereas the used one had 0.55 under the same conditions. It is clear that, during electrolysis, certain degrees of degradation occurred inside the membranes, probably due to the loss of ionic sites.

\subsection{Sorption experiments}

The Raipore 6030 membrane was tested in a series of experiments to determine its sorption characteristics. Known weights of a new and a used dry membrane were soaked in nitric acid at $25^{\circ} \mathrm{C}$ for $24 \mathrm{~h}$ at different concentrations. The used membrane had already been used for $40 \mathrm{~h}$ of EED for the experiment in the two previous sections. Once the membranes were well impregnated with the acid, they were washed thoroughly with water to remove all the surplus acid from the surface, and dried with a dry clean cloth. The membranes were placed in a container at a low pressure (near $1 \mathrm{~mm} \mathrm{Hg}$ ), in order to desorb all the acid and water adsorbed in the membrane. The acid and water extracted were collected in a cold trap and analyzed by standard volumetric analysis. Table 3 shows the calculated ratio of grams of $\mathrm{HNO}_{3}, \mathrm{H}_{2} \mathrm{O}$, and $\mathrm{HNO}_{3}+\mathrm{H}_{2} \mathrm{O}$ per gram of dry membrane for the new and used membranes. Regardless of whether the membrane had been 
Table 3

Data from sorption experiments using a Raipore 6030 membrane $^{\mathrm{a}}$

\begin{tabular}{|c|c|c|c|c|c|c|c|c|}
\hline \multirow{2}{*}{$\begin{array}{l}{\left[\mathrm{HNO}_{3}\right]} \\
(\%) \\
(\%) \text { in } \\
\text { solution }\end{array}$} & \multicolumn{4}{|c|}{$\begin{array}{l}\text { New membrane } \\
\text { (weight specie/weight of dried membrane) }\end{array}$} & \multicolumn{4}{|c|}{$\begin{array}{l}\text { Used membrane } \\
\text { (weight specie/weight of dried membrane) }\end{array}$} \\
\hline & $\begin{array}{l}\mathrm{HNO}_{3} / \\
\text { membrane }\end{array}$ & $\begin{array}{l}\mathrm{H}_{2} \mathrm{O} / \\
\text { membrane }\end{array}$ & $\begin{array}{l}\mathrm{HNO}_{3}+\mathrm{H}_{2} \mathrm{O} / \\
\text { membrane }\end{array}$ & $\begin{array}{l}\% \text { in } \\
\text { membrane }\end{array}$ & $\begin{array}{l}\mathrm{HNO}_{3} / \\
\text { membrane }\end{array}$ & $\begin{array}{l}\mathrm{H}_{2} \mathrm{O} / \\
\text { membrane }\end{array}$ & $\begin{array}{l}\mathrm{HNO}_{3}+\mathrm{H}_{2} \mathrm{O} / \\
\text { membrane }\end{array}$ & $\begin{array}{l}\% \text { in } \\
\text { membrane }\end{array}$ \\
\hline 51 & 0.08 & 0.049 & 0.129 & 62.1 & 0.057 & 0.034 & 0.091 & 62 \\
\hline 57.7 & 0.08 & 0.055 & 0.135 & 59.3 & 0.048 & 0.059 & 0.087 & 55.2 \\
\hline 62 & 0.097 & 0.041 & 0.138 & 70.2 & 0.054 & 0.022 & 0.076 & 70.6 \\
\hline 69 & 0.157 & 0.054 & 0.212 & 74.1 & 0.112 & 0.047 & 0.159 & 70.4 \\
\hline 74.5 & 0.166 & 0.054 & 0.220 & 75.4 & 0.109 & 0.036 & 0.145 & 75.2 \\
\hline 79 & 0.177 & 0.043 & 0.220 & 80.4 & 0.103 & 0.025 & 0.128 & 80.1 \\
\hline 84.9 & 0.252 & 0.009 & 0.261 & 96.5 & 0.157 & 0.046 & 0.203 & 77.4 \\
\hline 92 & 0.185 & 0.020 & 0.205 & 90.3 & 0.098 & 0.016 & 0.114 & 89.4 \\
\hline
\end{tabular}

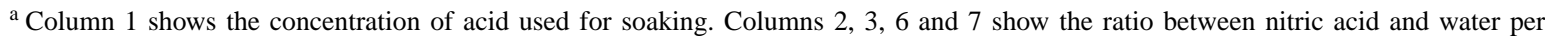
gram of membrane. Columns 4 and 8 show the total mass of components inside the membrane per gram of membrane. Columns 5 and 9 show the acid concentration inside the membrane.

used or not, the ratio of acid per unit weight of membrane increased with the concentration of the acid, where the membrane had previously been stabilized. The relationship was always smaller for a used membrane. This confirmed the fact that the used membrane lost some ionic or active sites during electrolysis. On the other hand, as was expected, the sorption of water became less as the acid concentration increased.

\subsection{Reaching a high nitric acid concentration by EED}

In another experiment, a new Raipore 6030 membrane was used to investigate the possibility of reaching $100 \%$ nitric acid concentration. The catholyte was replaced three times when its concentration diminished to $50 \%$ for a new $68.5 \%$ solution. The concentration in the anolyte increased to up to $92 \%$. Fig. 6 shows the change in the anolyte volume versus anolyte concentration. It can be seen that, at the beginning of electrolysis, the volume increased steadily; however, it reached a maximum when the acid concentration was $80 \%$. This increase in volume was followed by a rise in the anolyte concentration, indicating that the moles of nitrate rose faster than the moles of water in the anolyte. The back diffusion of nitrate ions to the catholyte increased after the acid concentration reached $80 \%$, due to the large difference in concentration between the two compartments. At below $80 \%$, the $\mathrm{NO}_{3}(\mathrm{H} 2 \mathrm{O})_{n}{ }^{-}$species was believed to have been transported through the membrane towards the anolyte by electrodiffusion. However, with more than $80 \%$ of acid in the anolyte, the back diffusion equalled the electrodiffusion of nitrate ions, and after this point, the concentration of acid increased only due to the consumption of water in the anode. This competitive process caused the flow of water to change direction.

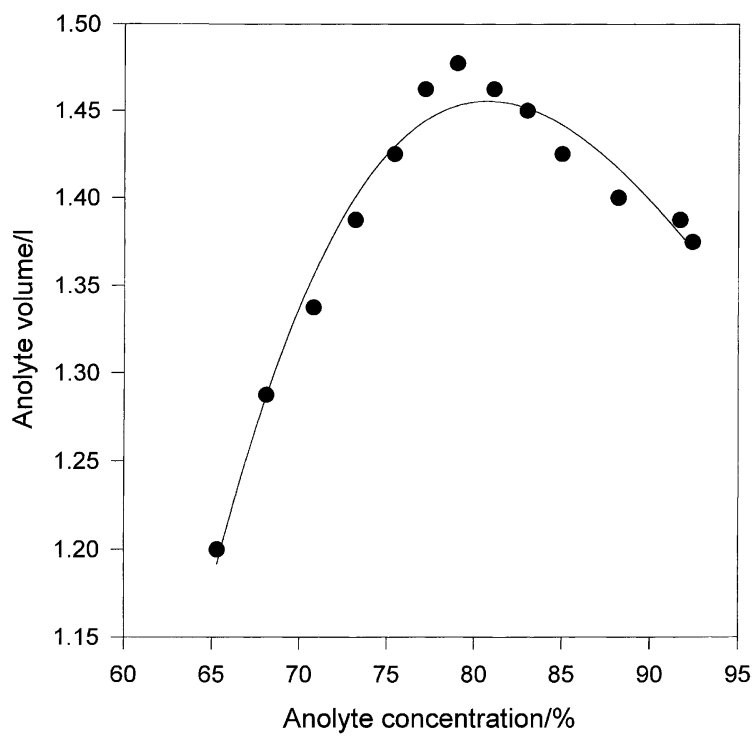

Fig. 6. Volume changes in the anolyte with the change in the anolyte concentration, when the anolyte concentration increased up to $92 \%$. The electrolysis was carried out at a density current of $300 \mathrm{~mA} \mathrm{~cm}^{-2}$ using a Raipore membrane 6030 from Pall. 
The change in moles of water in the anolyte per Faraday was

$\mathrm{DCE} \cdot n \mathrm{NO}_{3}{ }^{-}=-(1-\mathrm{DCE}) n \mathrm{H}^{+}-0.5$

where $n \mathrm{NO}_{3}{ }^{-}$is the number of moles of water associated with each nitrate ion transported through the membrane; $n \mathrm{H}^{+}$is the number of moles of water associated with each proton transferred through the membrane.

The 0.5 value arises from the consumption of $1 / 2$ mol of water per Faraday based on the assumption that the evolution of oxygen was the only anodic reaction. If $n \mathrm{NO}_{3}{ }^{-}=3$ and $n \mathrm{H}^{+}=1$, the point of zero change in volume was at the DCE value of 0.375 . The experimental DCE at $80 \%$ of $\mathrm{HNO}_{3}$ was 0.36 showing that, at this concentration, the amount of water dragged by each $\mathrm{NO}_{3}{ }^{-}$ion to the anolyte less the loss of water by back diffusion (due to each $\mathrm{H}^{+}$ion) equalled the water consumed in the anodic process.

The nitric acid-water mixtures are complex systems in which molecules of acid, its ions and the hydrate and non-hydratate species are all present together along with free water. Investigations on the absorption of infra-red and ultraviolet light by these mixtures [4] showed that, at $80 \%$ concentration, the $\mathrm{NO}_{2} \mathrm{OH} \cdot \mathrm{H}_{2} \mathrm{O}$ and $\mathrm{NO}_{2} \mathrm{OH} \cdot 3 \mathrm{H}_{2} \mathrm{O}$ species account for $70 \%$ of the fraction of total $\mathrm{HNO}_{3}$, the anhydrous $\mathrm{NO}_{2} \mathrm{OH}$ species for $25 \%$, and the ions $\mathrm{H}^{+}$and $\mathrm{NO}_{3}{ }^{-}$only for $5 \%$. This may suggest that the ionic species of the acid at these concentrations contribute very little to the back migration.

At $300 \mathrm{~mA} \mathrm{~cm}^{2}$, the evolution of $\mathrm{O}_{2}$ in the anolyte was $6.1 \times 10^{-3} \mathrm{~mol} \mathrm{~min}^{-1}$. Thus, the rate at which the water reacted at the anode, neglecting the density changes, was $0.0131 \mathrm{~h}^{-1}$. This change corresponds approximately to the $20 \%$ change in volume presented in Fig. 6, assuming that the evolution of oxygen was the only anodic reaction.

An interesting fact noted when characterizing the membrane was the comparison between the diffusional and electrodiffusional flows. The change in acid concentration due only to dialysis in the Raipore 6030 membrane was approximately $0.3 \mathrm{~mol} \mathrm{~h}^{-1}$. At an applied current density of $300 \mathrm{~mA} \mathrm{~cm}^{-1}$, the change in concentration was approximately $1.2 \mathrm{~mol} \mathrm{~h}^{-1}$ in the direction of the anolyte at a DCE of 0.80 . Thus, the diffusional flow was approximately $20 \%$ of the electrodiffusional flow.

\section{Conclusions}

The cathodic reaction of concentrated nitric acid produced a complex mixture of nitrogen oxides such as $\mathrm{N}_{2} \mathrm{O}_{4}, \mathrm{~N}_{2} \mathrm{O}_{3}$, and $\mathrm{NO}_{2}{ }^{-}$. The cathodic reduction of nitrate ions could be avoided using a three-compartment cell.

It was possible to break the nitric acid azeotrope mixture using any of the anionic membranes tested including (a) AFN7, (b) ARA, (c) Raipore 5035, (d) ACS, (e) AW, (f) Raipore 6030, when the difference in concentration between catholyte and anolyte did not exceed $5 \mathrm{M}$. The transportation of nitrate ions through these membranes increased in the same order in which they are listed above. The most efficient membrane was the Raipore 6030. However, the membrane needs to be tested in a series of long-term experiments.

\section{Acknowledgements}

The authors would like to express their gratitude to the Defence Evaluation Research Agency (DERA) and EPSRC for funding this work. The authors also thank J.K. Hammond, I. Gonzalez, M. Hart, and particularly V. Valuev for their help and useful discussions.

\section{References}

[1] D.J. Newman, Nitric Acid, in: Kirk- Othmer (Ed.), Encyclopaedia of Chemical Technology 3rd Edition. John Wiley, New York, USA, 1981, pp. 853-871.

[2] D.H. Lauriente, Marketing Research Report, Chemical Economics Handbook, September 1997.

[3] A.P. Murphy, Chemical removal of nitrate from water, Nature 350 (1991) 223-225.

[4] F.D. Miles, Nitric Acid Manufacture and Uses, Oxford University Press, London, 1961.

[5] M. Boudet-Dumy, A. Lindheimer, C. Gavach, Transport properties of anion exchange membranes in contact with hydrochloric acid solutions. Membranes for acid recovery by electrodialysis, J. Membr. Sci. 57 (1991) 57-68.

[6] J.P. Millington, in: D.S. Flett (Ed.), Ion Exchange Membranes, Ellis Horwood Ltd., Chichester, UK, 1983, p. 195.

[7] V.K. Indusekhar, G.S. Trivedi, B.G. Shan, Removal of nitrate by electrodialysis, Desalination 84 (1991) 213-221.

[8] T. Sata, T. Yamaguchi, K. Matsusaki, Anion exchange membranes for nitrate removal from groundwater by electrodialysis, J. Chem. Soc., Chem. Commun. 11 (1995) 1153-1154. 
[9] L.J. Andres, F.A. Riera, R. Alvarez, R. Audinos, Separation of strong acids by electrodialysis with membranes selective to monovalent ions - an approach to modeling the process, Can. J. Chem. Eng. 72 (1994) 848-853.

[10] B.J. Robbins, R.W. Field, S.T. Kolaczkowski, A.D. Lockett, Rationalisation of the relationship between proton leakage and water flux through anion exchange membranes, J. Membr. Sci. 118 (1996) 101-110.

[11] M.C.P.M. da Cunha, M. Weber, F.C. Nart, On the adsorption and reduction of $\mathrm{NO}_{3}{ }^{-}$ions at $\mathrm{Au}$ and $\mathrm{Pt}$ electrodes studied by in situ FTIR spectroscopy, J. Electroanal. Chem. 414 (1996) 163-170.

[12] K. Tanaka, N. Komeda, T. Matsui, Electrochemical assimilatory and dissimilatory reductions of $\mathrm{NO}_{3}{ }^{-}$and $\mathrm{NO}_{2}{ }^{-}$ via a possible NO intermediate, Inorg. Chem. 30 (1991) 3282-3288.

[13] H.-L. Li, J.Q. Chambers, D.T. Hobbs, Electroreduction of nitrate ions in concentrated sodium hydroxide solutions at lead, zinc, nickel and phthalocyanine-modified electrodes, J. Appl. Electrochem. 18 (1988) 454-458.

[14] D.H. Coleman, R.E. White, D.T. Hobbs, A parallel-plate electrochemical reactor model for the destruction of nitrate in alkaline waste solutions, J. Electrochem. Soc. 142 (1995) 1152-1161.

[15] O.A. Petrii, T.Y. Safonova, Electroreduction of nitrate and nitrite anions on platinum metals: a model process for elucidating the nature of the passivation by hydrogen adsorption, J. Electroanal. Chem. 331 (1992) 897-911.

[16] K. Jha, J.W. Weidner, Evaluation of porous cathodes for the electrochemical reduction of nitrates and nitrites in alkaline waste streams, J. Appl. Electrochem. 29 (1999) 13051315.

[17] X. Xing, D.A. Scherson, C. Mak, The electrocatalytic reduction of nitrate mediated by underpotential-deposited cadmium on gold and silver electrodes in acid media, J. Electrochem. Soc. 137 (1990) 2166-2175.

[18] K.H. Heckner, Potentiostatic switching experiment for the cathodic reduction of nitrous acid in perchloric acid with the addition of nitric acid, J. Electroanal. Chem. 44 (1973) 920.

[19] D. Hernandez, R. Dotson, Electrochemical reduction of nitric acid to hydroxylamine nitrate, UK Patent Application GB $2,211,858$ A.
[20] J.E. Harrar, R. Quong, L.P. Rigdon, R.R. Mcguire, Scale-up studies of the electrosynthesis of dinitrogenpentoxide in nitric acid, J. Electrochem. Soc. 144 (1997) 2032-2044.

[21] J.E. Harrar, R.K. Pearson, Electrosynthesis of $\mathrm{N}_{2} \mathrm{O}_{5}$ by controlled-potential oxidation of $\mathrm{N}_{2} \mathrm{O}_{4}$ in anhydrous $\mathrm{HNO}_{3}$, J. Electrochem. Soc. 130 (1983) 108-112.

[22] D. Robinson, in: J.D. Genders, D. Pletcher (Eds.), Electrosynthesis-From Laboratory, to Pilot, to Production, The Electrosynthesis Co., Buffalo, NY, 1990.

[23] C.J. Brown, D. Pletcher, F.C. Walsh, J.K. Hammond, D. Robinson, Local mass transport in the FMO1 electrolyser, J. Appl. Electrochem. 22 (1992) 613-619.

[24] C.J. Brown, D. Pletcher, F.C. Walsh, J.K. Hammond, D. Robinson, Studies of space-averaged mass transport in the FMO1-LC laboratory electrolyser, J. Appl. Electrochem. 23 (1993) 38-43.

[25] Y. Lorrain, G. Pourcelly, C. Gavach, Influence of cations on the proton leakage through anion-exchange membranes, J. Membr. Sci. 110 (1996) 181-190.

[26] F. Aouad, A. Lindheimer, C. Gavach, Transport properties of electrodialysis membranes in the presence of $\mathrm{Zn}^{+2}$ complexes with $\mathrm{Cl}^{-}$, J. Membr. Sci. 123 (1997) 207-223.

[27] A.T. Cherif, C. Gavach, T. Cohen, P. Dagard, L. Albert, Sulfuric acid concentration with an electro-electrodialysis process, Hydrometallurgy 21 (1988) 191-201.

[28] G. Pourcelly, I. Tugas, C. Gavach, Electrotransport of sulphuric acid in special anion exchange membranes for the recovery of acids, J. Membr. Sci. 97 (1994) 99-107.

[29] T.A. Davis, J.D. Genders, D. Pletcher, A First Course in Ion Permeable Membranes, Alresford Press, Hants, England, 1997.

[30] A. Arber, personal communication, Defence Research Environmental Agency (DERA), 1999.

[31] A.I. Vogel, Textbook of Quantitative Inorganic Analysis, 4th Edition, Longmans, New York, 1981.

[32] K. Kneifel, G. Luhrs, H. Wagner, Nitrate removal by electrodialysis for brewing water, Desalination 68 (1988) 203-209.

[33] R. Rautenbach, W. Kopp, G. Van Opbergen, R. Hellekes, Nitrate reduction of well water by reverse osmosis and electrodialysis - studies on plant performance and costs, Desalination 65 (1987) 241-258.

[34] D. Pletcher, F. Walsh, Industrial Electrochemistry, 2nd Edition, Chapman \& Hall, London, 1990. 